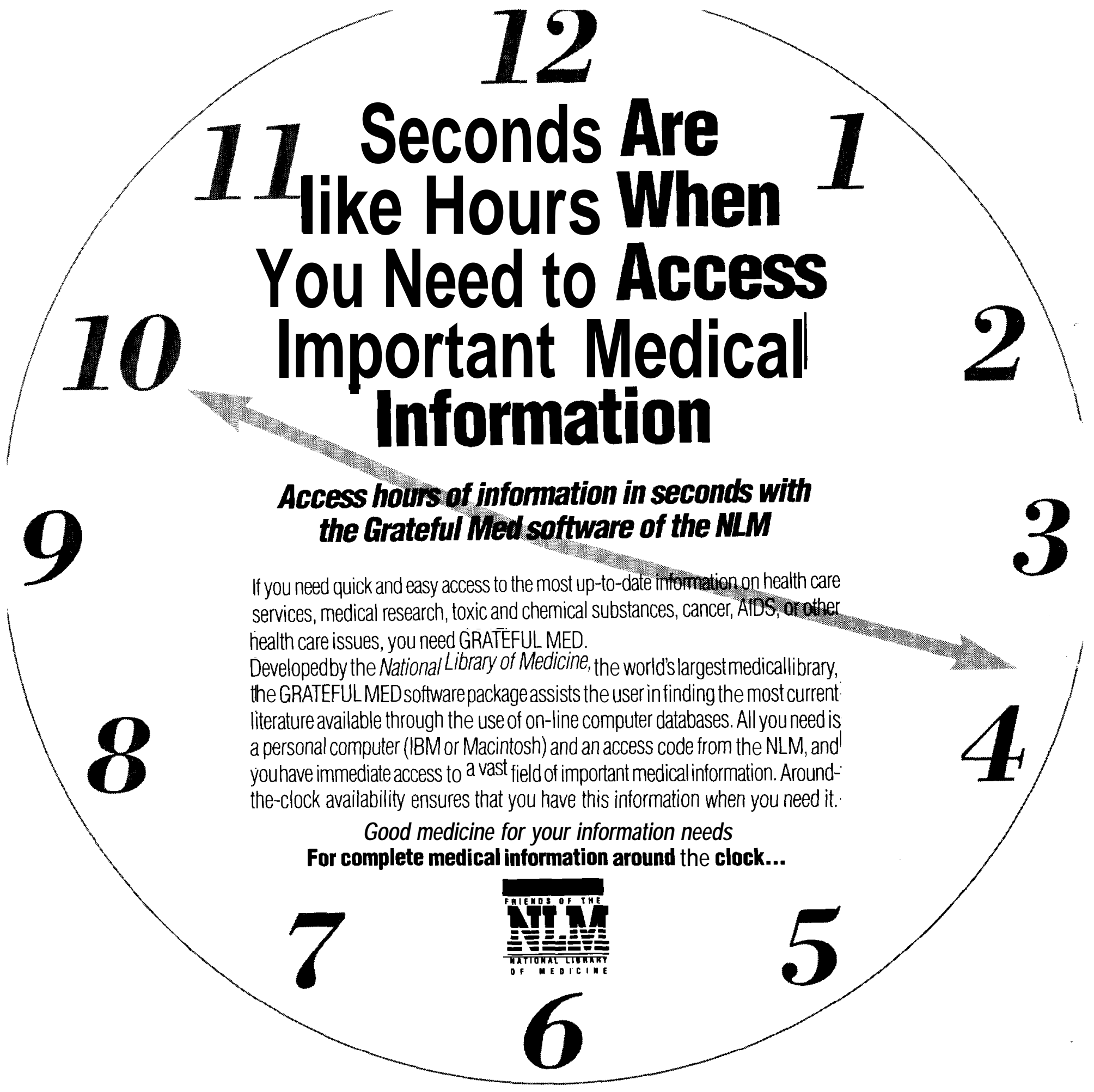

For further information about the NLM's Grateful Med Software Service, just fill out this coupon. Clip and mail to:

The National Library of Medicine Public Information Office Bethesda, Maryland 20894
$\mathrm{Cl}$ Please send me more information about the NLM's Grateful Med software package $\square$ Please send me more information about the Friends of the National Library of Medicine

$\begin{array}{lll}\text { City } & \text { State } & \text { ZIP }\end{array}$

Merck Development of this public service Company Foundation

\section{Telephone No.}

I saw this ad in 

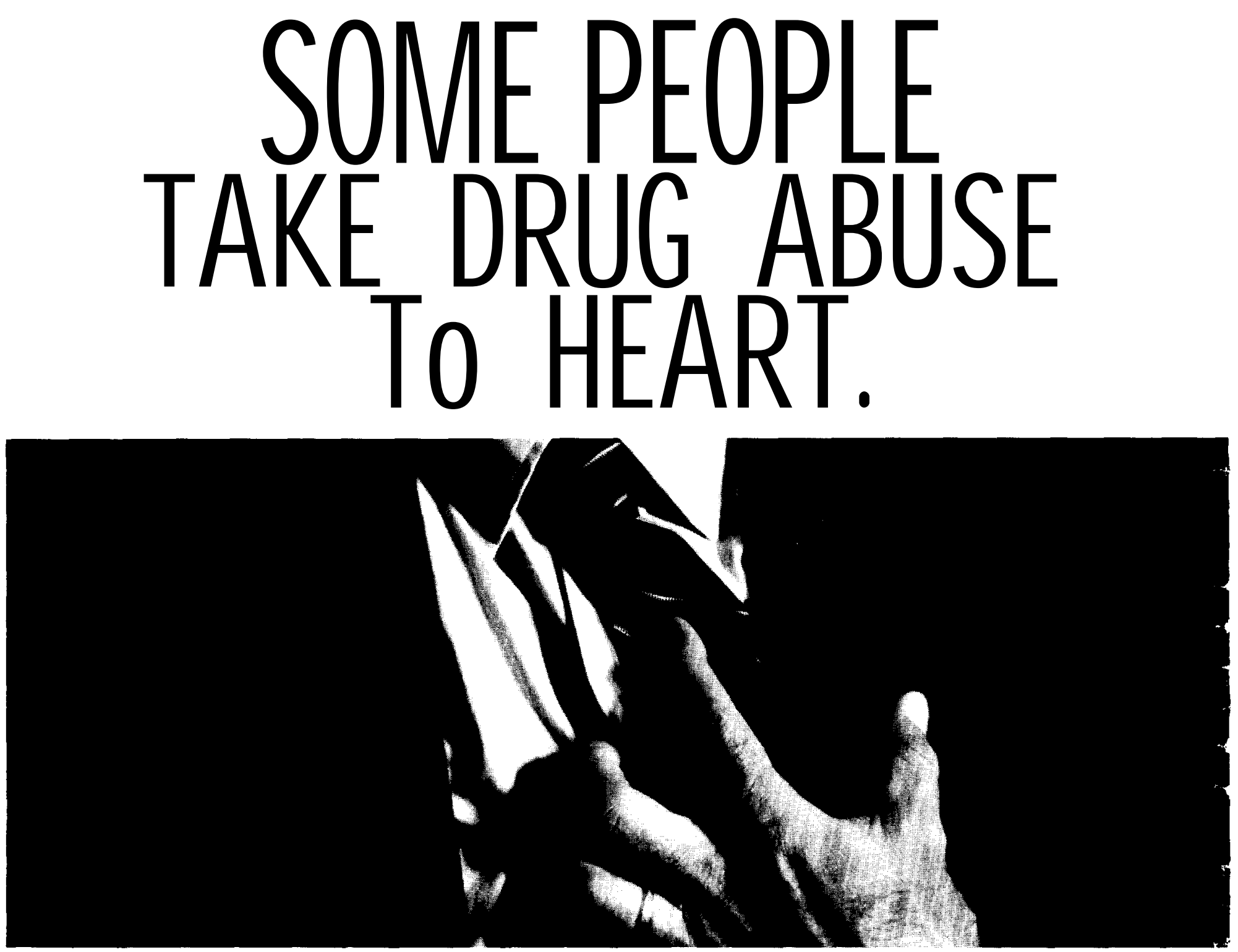

Most cocaine users are so dedicated to the drug that what it does to their hearts never enters their minds. They don't realize that every time they use cocaine, they put themselves at risk for such potentially fatal cardiovascular complications as hypertensive crisis.. . myocarditis.. .myocardial infarction ...ventricular tachycardia.. .ventricular fibrillation.. . even cardiac arrest.

Chances are, at least some of these people are your patients. And many of them may feel more comfort- able telling a nurse what they can't-or won't-tell a doctor. That's why your role becomes critical in helping suspected drug abusers understand what illegal drug use does to their bodies. As key members of the health care team, nurses can make a difference in helping to curb drug abuse, and in preventing some of its deadliest consequences. The next time you suspect a patient may be using cocaine-or any

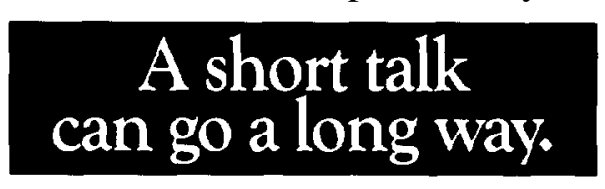

illegal substancehave a heart-to-heart talk about the damage these drugs can do. 